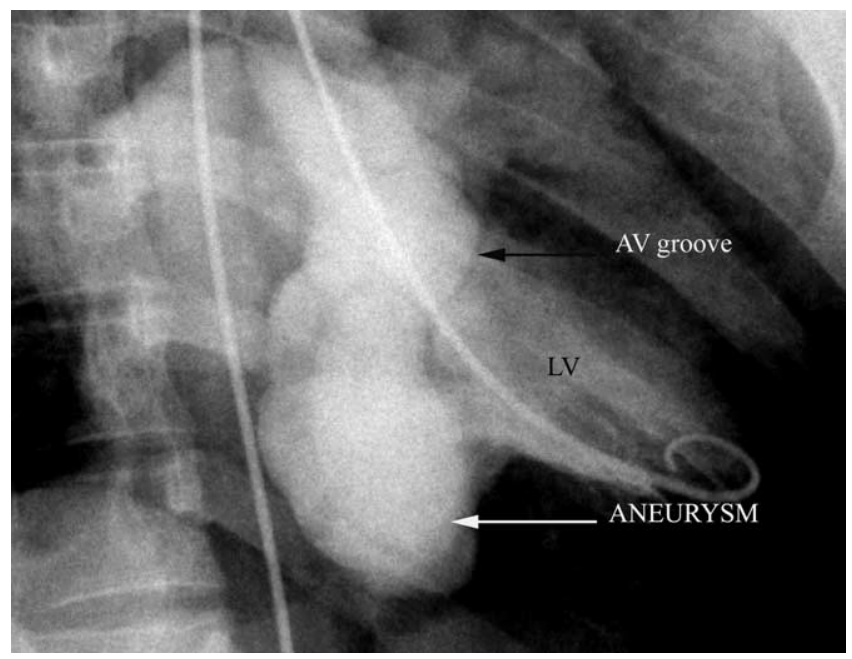

Figure 2. Left ventricular angiogram of the relationship of the atrioventricular groove to the aneurysm: white arrow, aneurysm; black arrow, atrioventricular groove. AV groove, Atrioventricular groove; $L V$, left ventricle. the circumflex, a transatrial approach would no doubt be ideal. In cases similar to ours, a direct approach through a left thoracotomy is a good alternative because the circumflex artery can be clearly visualized and protected. Moreover, most patients do not have significant mitral regurgitation and might not require an additional mitral valve procedure

Our approach, which is based on the relationship of the circumflex coronary artery to the neck of the aneurysm as demonstrated on a preoperative angiogram, appears to be safe and will result in significant reduction in mortality and morbidity in managing this rare and difficult condition, particularly in parts of the world outside Africa.

\section{References}

1. Abrahams DG, Barton CJ, Cockshott WP, et al. Annular subvalvular left ventricular aneurysms. $Q$ J Med. 1962;31:345-60.

2. Cockshott WP, Antia A, Ikeme A, Uzodike VO. Annular subvalvar left ventricular aneurysms. Br J Radiol. 1967;40:424-35.

3. Antunes MJ. Submitral left ventricular aneurysms: correction by a new transatrial approach. J Thorac Cardiovasc Surg. 1987;94:241-5.

4. Wolpowitz A, Arman B, Barnard M, Barnard C. Annular subvalvar idiopathic left ventricular aneurysms in the black African. Ann Thorac Surg. 1979;27:350-4.

\title{
Sternal resection and reconstruction after renal cell carcinoma metastatic to the sternum
}

Jeremy W. Pyle, BS, ${ }^{a}$ Jennifer L. Ash, MD, ${ }^{b}$ Syed M. Hussain, MD, ${ }^{b}$ Nicole Reid, MD, and Richard C. Anderson, MD, ${ }^{b, c}$ Peoria, III

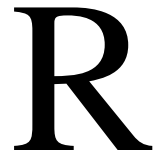

enal cell carcinoma is neither uncommon nor easy to detect. For this reason, coupled with the highly vascular nature of this tumor, it is frequently discovered incidentally or through workup of a metastasis. Literature from $1972^{1}$ and $1981^{2}$ detail 3 patients who underwent both nephrectomy and sternal resection for a metastatic renal cell carcinoma and were asymptomatic after 5 years. Since that time,

\footnotetext{
From the University of Illinois College of Medicine at Peoria, ${ }^{a}$ Department of Surgery $^{\mathrm{b}}$ and Section of Cardiothoracic Surgery, ${ }^{\mathrm{c}}$ Peoria, Ill.

Received for publication July 22, 2004; accepted for publication Aug 23, 2004.

Address for reprints: Richard C. Anderson, MD, FACS, University of Illinois College of Medicine at Peoria, Department of Surgery, North Building, 2nd Floor, 624 NE Glen Oak Ave, Peoria, IL 61603-3135.

J Thorac Cardiovasc Surg 2005; 129:1177-8

$0022-5223 / \$ 30.00$

Copyright $\odot 2005$ by The American Association for Thoracic Surgery doi:10.1016/j.jtcvs.2004.08.050
}

written material on the topic of isolated renal cell metastases has been sparse. Given the current state of prosthetic materials and surgical expertise, in the presence of an isolated metastatic lesion to the sternum, resection and reconstruction with intent to palliate or obviate disease is preferred. We report on our experience with one case of a singular metastatic focus in the sternum and the sternectomy and reconstruction used in treatment.

\section{Clinical Summary}

A 47-year-old woman had pain overlying the sternum. Clinical examination at that time showed a tender protuberance with fullness across the manubrium and proximal sternum. Computed tomography of the chest and abdomen was obtained and revealed a $2.2 \times 4.5-\mathrm{cm}$ sternal mass (Figures 1 and 2) and a $5.8 \times 6.4-\mathrm{cm}$ left renal hilar mass invading the left renal vein. A subsequent positron emission tomographic scan showed hypermetabolism in the kidney and sternum. Biopsy of the sternal mass was performed, and pathology revealed metastatic renal cell carcinoma. Given that she showed no overt or radiologic signs of other lesions, the patient underwent left nephrectomy and was prepared for sternal resection and reconstruction. 


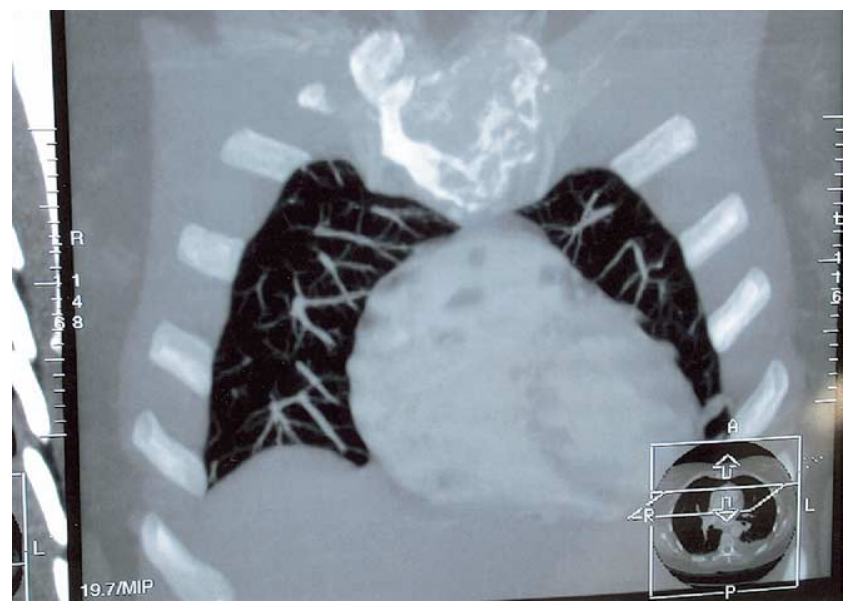

Figure 1. Three-dimensional recreation of the thorax with sternal lesion evident.

On opening a midline sternal incision, a large bulge with clearly visible neovascularity was present at the superior aspect of the sternum. Dissection to remove this lesion began approximately $2 \mathrm{~cm}$ lateral to the internal thoracic artery and continued through the superior 3 ribs bilaterally $3.5 \mathrm{~cm}$ distal to the sternal articulation, the associated intercostal muscles, both clavicles $5 \mathrm{~cm}$ from their points of articulation, and the supraclavicular lymph nodes. This resection left a total defect of $0.5 \times 10.2 \times 1.0 \times 3.5 \mathrm{~cm}$. Pathologic examination of the sternal tissue revealed a yellow low-grade renal cell carcinoma with a clear margin. Supraclavicular nodes were without disease. After the placement of two $28 \mathrm{~F}$ drains in the pleural cavity, repair was begun. By using Prolene mesh (Ethicon, Inc, Somerville, NJ) shaped and contoured to fill the sternal void, a bilaminate methylmethacrylate sternal shield was fashioned, and the sternum was thus reconstructed with good fixation. A bilateral pectoralis advancement flap was then used to close the defect. The patient's postoperative course was uneventful, and the patient was discharged on the seventh hospital day. Continuing care includes local radiation to the chest wall and systemic immunotherapy.

Six months after sternal resection and reconstruction, the patient has maintained excellent range of motion without instability.

\section{Discussion}

Renal cell carcinoma accounts for approximately 3\% of adult malignancies, with about 1 of 4 presenting with metastases, $95 \%$ of which are multiple. ${ }^{3}$ When the diagnosis involves disease in the sternum, resection and reconstruction with a rigid prosthesis has been shown to provide both palliation and prolonged survival. ${ }^{4}$ By using Prolene, Marlex C.R. Bard, Inc, Billerica, Mass), or Vicryl (Ethicon) nets or Gore-Tex (W. L. Gore \& Associates, Inc, Flagstaff, Ariz) patches and a rigid support, one prevents postoperative paradoxical movement of the chest wall while providing adequate precordial protection. In addition, sternal metastases are different from other bony metastases,

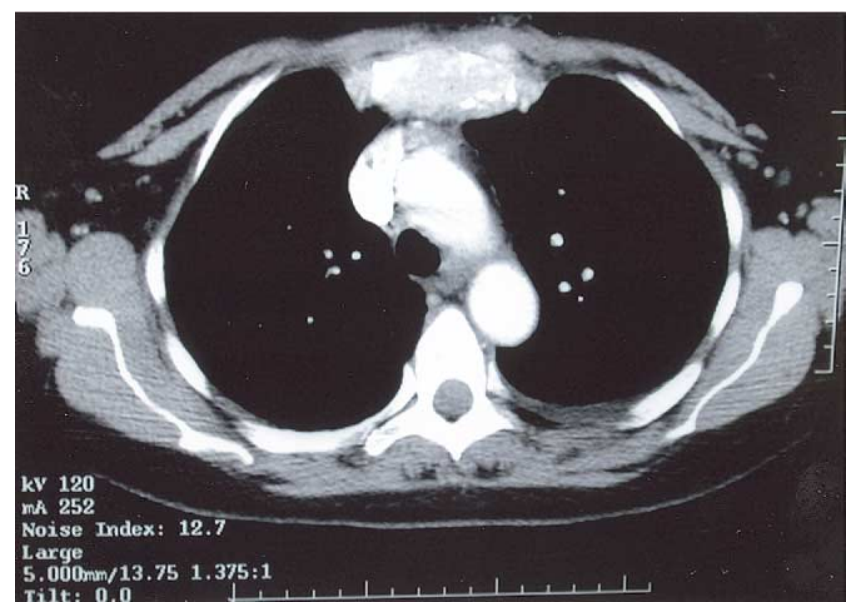

Figure 2. Computed tomographic scan showing lesion in the sternum.

such as vertebral metastases, in that their lack of an expansive communicative vasculature, like those provided by the paravertebral venous plexus and other venous systems, means they might remain solitary for an extended time. ${ }^{5}$

When, in 1966, Drs Yale and Wear continued a challenge to the old thinking that resections of sternal metastases were futile, they admitted that the sometimes long dormant nature of renal cell carcinoma ought to steer one away from pronouncing a cure with resection. $^{2}$ Even then, however, in the absence of today's technology, removing the tumor was the best way to prolong and preserve a high quality of life. Additional benefit comes from active research regarding the use of immunotherapy. Such therapy, when combined with a means of reducing tumor bulk, can provide significant symptomatic relief.

In this case our patient presented with renal cell carcinoma invading the renal vein and a concurrent but isolated lesion in the midline anterior chest wall. We elected to perform sternal resection and reconstruction with a Prolene methylmethacrylate sandwich, achieved good fixation intraoperatively, and, after a 7-day hospital course and 6 months after the operation, the patient is doing very well.

\section{References}

1. Yale CE, Wear JB. Subtotal sternal resection for metastatic renal cell carcinoma. Arch Surg. 1972;105:87-9.

2. Estera AS, Platt MR, Mills LJ, Shaw RR. Pulsatile sternal tumor: report of three cases and a review of the literature. Ann Thorac Surg. 1981; 31:244-50.

3. Curti , Brendan D. Renal cell carcinoma. JAMA 2004;292:97-1000.

4. Incarbone M, Nava M, Lequaglie C, Ravasi G, Pastorini U. Sternal resection for primary and secondary tumors. J Thorac Cardiovasc Surg. 1997;114:93-9.

5. Noguchi S, Miyauchi K, Nishizawa Y, Imaoka S, Koyama H, Iwanaga T. Results of surgical treatment for sternal metastasis of breast cancer. Cancer. 1988;62:1397-401. 